\title{
Qualidade de vida no serviço público: o caso dos servidores efetivos do Senado Federal
}

\author{
Paulo Ricardo dos Santos Meira ${ }^{1}$ \\ Jairo Alves da Silva Junior ${ }^{2}$
}

\begin{abstract}
Resumo
Este estudo tem como objetivos aprofundar a compreensão sobre qualidade de vida no serviço público e, especificamente, avaliar a qualidade de vida de um grupo de servidores efetivos do Senado Federal; igualmente levantar os principais problemas que prejudicam essa qualidade, fornecer dados estatísticos sobre saúde e doença desses servidores e propor melhorias nos programas preventivos oferecidos pela Instituição. Para tanto, aplicou-se o questionário QVS-80 com 231 servidores voluntários, com retorno de 226 questionários válidos. A análise dos dados obtidos permitiu concluir que a qualidade de vida é considerada satisfatória, em uma escala de cinco pontos, que varia de muito insatisfatório até muito satisfatório. No entanto, a despeito da qualidade de vida ser percebida como satisfatória, a análise revelou problemas como elevado número de servidores sedentários e obesos, servidores com sintomas relacionados a distúrbios do humor, ansiedade e depressão (mais da metade). A conclusão aponta para a importância de realização de campanhas e programas preventivos para diminuir a prevalência desses problemas, diminuir os custos gerados pelo afastamento por licenças médicas com pessoal e melhorar a qualidade de vida do quadro de servidores efetivos do Senado Federal.
\end{abstract}

Palavras-chave: Qualidade de vida. Senado Federal. QVS-80. Programas preventivos. Serviço público.

\begin{abstract}
This study aims to deepen the understanding of the quality of life in public service, specifically of a group of civil servants of Brazilian Federal Senate, to gather the main problems that affect this quality, to provide statistical data about illness and health and to propose improvements in prevention programs offered by the Institution. Therefore, the QVS-80 questionnaire was applied in 231 volunteers resulting in 226 valid questionnaires. The data analysis, allowed to know that the quality of life is considered satisfactory on a five-points scale ranging from very unsatisfactory to very satisfactory. However, despite the alleged satisfactory quality of life, the analysis revealed problems such as large number of obesity and sedentarism; and more than half of servers with symptoms related to mood disorders, anxiety and depression. The conclusion pointed to the importance of campaigns and prevention programs to reduce the prevalence of these problems, reduce the costs generated by medical leave absence and improve the quality of life of the civil servants of Senate.
\end{abstract}

Keywords: Quality of life. Brazilian Federal Senate. QVS-80. Prevention programs.

\section{Introdução}

O presente trabalho versa sobre um dos grandes desafios gerenciais no setor público, qual seja, a qualidade de vida do corpo funcional. Avaliar, monitorar e manter uma satisfatória qualidade de vida de seus servidores resulta, em última análise, em economia aos cofres públicos, por reduzir o absenteísmo e licenças médicas, além de propiciar o aumento da

\footnotetext{
${ }^{1}$ Analista de Comunicação do Senado Federal, Doutor em Marketing. Professor do Instituto Legislativo Brasileiro e da EDAN/UCSA. paulomeira@gmail.com

${ }^{2}$ Médico Psiquiatra. Analista Legislativo e Analista Judiciário - Medicina. Perito das Juntas Médicas do Senado e do STJ.paulomeira@gmail.com
} 
produtividade e da qualidade dos serviços, por possuir um quadro de pessoal mais saudável, mais motivado e que adoece menos. O foco do presente trabalho é verificar a qualidade de vida de uma amostra de servidores efetivos do Senado Federal por meio da análise das respostas obtidas no questionário QVS-80 aplicado. Optou-se por delimitar este estudo apenas aos servidores efetivos, já que, entre os comissionados, existe grande rotatividade, característica que limita a ação de trabalhos preventivos a longo prazo. Esse questionário apresenta oitenta questões nos seguintes quesitos - informações pessoais, estilo de vida e saúde, atividade física, avaliação do ambiente ocupacional e avaliação da qualidade de vida na visão do pesquisado.

A justificativa do estudo dá-se pela crescente preocupação das empresas e instituições públicas com a produtividade e diminuição dos custos. Busca-se cada vez mais aumentar as metas, diminuir os prazos para a execução de trabalhos, sem, no entanto, diminuir a qualidade do serviço (MONACO; GUIMARÃES, 2000). Evidentemente, para que isso ocorra de maneira equilibrada e harmônica, é fundamental conhecer as capacidades e limitações dos funcionários e servidores.

A capacidade de produção do trabalhador depende de vários fatores. Podemos citar alguns, como motivação para o trabalho, condição física (presença ou não de patologia e sua gravidade), tempo para descanso e lazer, condição financeira, suporte familiar. No intuito de conhecer melhor os trabalhadores e suas condições de saúde, foram desenvolvidas ferramentas que pretendem avaliar o nível de qualidade de vida e, com isso, detectar problemas que podem ser alvos de programas preventivos e programas curativos.

No Senado Federal, o Programa de Qualidade de Vida (PQV) foi criado pelo Ato do 10 Secretário no 30, de $2003^{3}$. Dessa forma, foi possível passar de uma abordagem unicamente curativa para preventiva; da avaliação pericial, reabilitação e readaptação, para o enfoque mais amplo, englobado pelo conceito de Qualidade de Vida no Trabalho (QVT). Em 2005, o Programa foi transformado em Serviço de Qualidade de Vida e Reabilitação Funcional (SEQVR) ${ }^{4}$, sob a direção da Secretaria de Recursos Humanos (SERH), recentemente denominada Secretaria de Gestão de Pessoas (SEGP).

A busca pela qualidade de vida no trabalho implica a conciliação de duas posições: as necessidades dos trabalhadores quanto à satisfação no trabalho e os interesses das organizações quanto à produtividade e qualidade do trabalho (LACAZ, 2000). O Serviço de Qualidade de Vida e Reabilitação Funcional (SEQVR) tem como missão construir ações de promoção da saúde e de valorização do servidor, visando à qualidade de vida e ao cumprimento da missão institucional. Tem como objetivos promover a saúde dos trabalhadores e a satisfação no trabalho; colaborar com o ganho de produtividade - por intermédio da redução dos índices de absenteísmo, das licenças médicas e da melhoria nas esferas

\footnotetext{
${ }^{3}$ Boletim Administrativo do Senado Federal (BASF) no 2879, de 13 de novembro de 2003.

${ }^{4}$ Ato da Comissão Diretora no 2/2005, de 4 de fevereiro de 2005 (BASF $n^{\circ} 3170$ Suplementar, de 4 de fevereiro de 2005).
} 
psicossociais, como motivação no trabalho e comprometimento organizacional (SENADO FEDERAL, 2013a).

Diante de dados levantados sobre absenteísmo e licenças médicas na instituição, foram implantados alguns programas preventivos. Atualmente, o Serviço de Qualidade de Vida apresenta os seguintes programas: Alimento e Saúde, Caminhos para a Aposentadoria, Orientação Financeira, Pesquisa de Clima Organizacional, Programa de Atenção ao Uso de Álcool e Drogas (Progad), Pró-Saúde Ocupacional, Desenvolvimento de Equipes de Trabalho, Acompanhamento Funcional e Dignidade e Respeito no Trabalho (SENADO FEDERAL, 2014).

Com a aplicação do questionário de qualidade de vida e a análise de seus resultados, pretende-se identificar tais problemas e ter dados mais consistentes e objetivos. Com isso, será possível corrigir e aprimorar os programas existentes, além de propor a criação de outros que possam ser adequados à demanda apresentada.

Tendo em vista os diversos fatores que influenciam positiva e negativamente a qualidade de vida das pessoas, e a necessidade de aprimorar os programas preventivos e ações administrativas, os quais podem contribuir para a melhora da qualidade de vida do servidor efetivo do Senado Federal, este trabalho, por meio da aplicação e análise do questionário QVS80 sobre qualidade de vida, pretende responder à seguinte questão-problema: "Como se classifica a qualidade de vida da amostra pesquisada de servidores efetivos do Senado Federal?".

O principal objetivo deste estudo foi o de avaliar a qualidade de vida dos servidores efetivos do Senado Federal. Mais especificamente, buscou-se levantar os principais problemas à qualidade de vida dos servidores e comparar as taxas de prevalência de sedentarismo, atividade física, consumo de tabaco, consumo de bebida alcoólica e prevalência de doenças crônicas dos pesquisados com as taxas da população brasileira. E, ainda, testar uma ferramenta para futura coleta de dados estatísticos sobre saúde e doenças dos servidores, para que o Senado possa, gradativamente, através de ações específicas e programas preventivos, melhorar a qualidade de vida do servidor e, consequentemente, melhorar a produtividade e diminuir o absenteísmo e o custo com pessoal. Por fim, verificar a necessidade de programas preventivos e campanhas para a obtenção de melhor qualidade de vida.

\section{Referencial teórico}

Historicamente, a expressão Qualidade de Vida foi se transformando, e isso ocorre até hoje. Não há consenso com relação ao conceito, já que, muitas vezes, essa expressão aparece com sentido genérico e abrange vários significados que expressam "experiências e valores individuais e coletivos", frequentemente subjetivos, modificados de acordo com a época, a cultura e diferentes locais. Assim, pode-se dizer que é uma "[...] construção social com relatividade cultural" (MINAYO; HARTZ; BUSS, 2000, p. 8).

Segundo Minayo, Hartz e Buss (2000), as primeiras referências relacionando saúde e qualidade de vida surgiram nos séculos XVIII e XIX, com o surgimento da medicina social. Já no campo da economia, a expressão começou a ser utilizada em 1958 por J.K. Galbraith, para 
defender a tese de que uma boa qualidade de vida é resultado dos "[...]efeitos dos objetivos econômicos quantitativos, mas também a melhoria em termos qualitativos das condições da vida humana" (SOUZA; CANDIOTO, 2013, p. 13). Tais condições incluem "[...] hábitos saudáveis, cuidado com o corpo e alimentação, relacionamentos prazerosos, tempo para o lazer e vários outros hábitos que façam o indivíduo se sentir bem, trazendo boas consequências e utilizando o humor para lidar com situações de estresse no dia a dia". Incluem também "objetivos de vida que propiciam ao indivíduo sentir que tem controle sobre sua própria vida".

Para Buss (2000, p. 167),

\begin{abstract}
A saúde é produto de um amplo espectro de fatores relacionados com a qualidade de vida, incluindo um padrão adequado de alimentação e nutrição, e de habitação e saneamento; boas condições de trabalho; oportunidades de educação ao longo de toda a vida; ambiente físico limpo; apoio social para famílias e indivíduos; estilo de vida responsável; e um espectro adequado de cuidados de saúde. Suas atividades estariam, então, mais voltadas ao coletivo de indivíduos e ao ambiente, compreendido num sentido amplo, de ambiente físico, social, político, econômico e cultural, através de políticas públicas e de condições favoráveis ao desenvolvimento da saúde (as escolhas saudáveis serão as mais fáceis) e do reforço (empowerment) da capacidade dos indivíduos e das comunidades.
\end{abstract}

A estas noções de saúde e de economia, foram acrescentados, na década de 1970, questionamentos com relação aos modelos de bem-estar que danificam a natureza, o que ficou conhecido como movimento ambientalista (MINAYO; HARTZ; BUSS, 2000). Para este movimento, as noções de bem-estar e qualidade de vida deveriam estar associadas à preocupação com o meio ambiente e o desenvolvimento sustentável. Os conceitos de promoção da saúde, na década de 70, de acordo com Lalonde (1974, apud MINAYO; HARTZ; BUSS, 2000, p. 9) tomavam como base "1) o estilo de vida; 2) os avanços da biologia humana; 3 ) o ambiente físico e social; e 4) serviços de saúde". Desde então, o conceito tem sido debatido e ampliado. "Valores não materiais, como realização pessoal, inserção social e felicidade", passaram a ser considerados na avaliação (elementos subjetivos).

É preciso considerar que há um patamar mínimo na avaliação da qualidade de vida no tocante à obtenção das necessidades básicas da vida humana, como "[...] alimentação, acesso à água potável, habitação, trabalho, educação, saúde e lazer" (MINAYO; HARTZ; BUSS, 2000, p. 10). São elementos mais objetivos, materiais e que estão atrelados à noção relativa de conforto e bem-estar. Esses elementos, por serem objetivos, podem ser medidos com mais facilidade com auxílio de ferramentas como o IDH (Índice de Desenvolvimento Humano), entre outras.

As ferramentas mais novas englobam esses valores objetivos, contudo buscam avaliar também a "[...] percepção do indivíduo de sua posição na vida, no contexto da cultura e do sistema de valores em que vive e em relação aos seus objetivos, expectativas, padrões e preocupações" (MINAYO; HARTZ; BUSS, 2000, p. 13). É o caso da ferramenta desenvolvida pelo grupo de qualidade de vida da Divisão de Saúde Mental da Organização Mundial de Saúde (WORLD HEALTH ORGANIZATION, 1997). Nela, os questionários de qualidade de vida desenvolvidos buscam avaliar os seguintes domínios: a) físico, b) psicológico, c) de independência, d) relações sociais, e) meio ambiente e f) espiritualidade/crenças pessoais (MINAYO; HARTZ; BUSS, 2000, p. 13). 
O Índice de Desenvolvimento Humano (IDH) surgiu no Programa das Nações Unidas para o Desenvolvimento, proposto pelo economista Mahbud ul Haq, em 1990, com o objetivo de "[...]desviar o foco do desenvolvimento da economia e da contabilidade de renda nacional para políticas centradas em pessoas". A avaliação do IDH combina três dimensões (desde o relatório de 2010) - "uma vida longa e saudável (expectativa de vida ao nascer)", "o acesso ao conhecimento (anos meios de estudo e anos esperados de escolaridade)" e "um padrão de vida adequado (Produto Interno Bruto - PIB - per capita)", e é comumente utilizado para medir o impacto das políticas econômicas na qualidade de vida de uma determinada localidade (PROGRAMA DAS NAÇÕES UNIDAS PARA O DESENVOLVIMENTO, 2013).

Os programas de qualidade de vida no trabalho focalizam o efeito do trabalho sobre os empregados, que vão além das metas organizacionais, além da utilização da participação dos trabalhadores na resolução de problemas e na tomada de decisões (NASCIMENTO, 2013). Esse tema tem sido intensamente desenvolvido nos últimos anos, já que, no mundo do trabalho contemporâneo, a valorização das pessoas passou a ser de suma importância, o que possibilita “[...] maior atuação no processo de produção, aumento da motivação no trabalho, garantindo uma maior qualidade do produto, bem como o favorecimento da saúde mental e física do trabalhador" (NASCIMENTO, 2013).

Para Lacaz (2000), não se poderia tratar de qualidade do produto sem abranger, igualmente, a qualidade dos ambientes e das condições de trabalho em que esse produto é gerado. Assim, o foco desses programas não pode estar no empregado individualmente, mas, sim, na necessidade de arranjos flexíveis de trabalho, seja no design físico, seja na programação de horas de trabalho, adaptando-os às necessidades de cada trabalhador. Ou seja, os programas de qualidade de vida, na elaboração de suas ações, devem levar em conta as condições e a organização do trabalho. Além disso, é importante considerar que os trabalhadores de uma determinada organização têm responsabilidades que vão além das previstas nos desenhos do cargo, as quais podem influir nos seus comportamentos no trabalho.

Por isso, empresas e instituições devem pensar a saúde do trabalhador ou servidor na perspectiva da promoção da saúde no trabalho, a fim de não só de cuidar das pessoas que formam a organização, mas também para reduzir custos com dias de afastamento e com a retirada precoce do trabalho por invalidez e acidentes. Assim, melhorar a qualidade de vida no trabalho é um meio de reduzir taxas de absenteísmo, rotatividade, acidentes e queixas (COCCO, 2001 apud NASCIMENTO, 2013).

Outro ponto que deve ser levado em consideração pelos programas de Qualidade de Vida diz respeito à administração de conflitos tanto na vida pessoal como profissional dos trabalhadores, como alerta Robbins (2005), que, em sua obra, apresenta algumas estratégias que os administradores podem utilizar para amenizar tais conflitos. Na seção a seguir, descreve-se a metodologia usada neste trabalho. 


\section{Metodologia}

Para a coleta de dados, foi utilizado, com adaptações, o Questionário de Avaliação da Qualidade de Vida e de Saúde (QVS-80) proposto por Leite et al. (2012). Optou-se por este intrumento por duas razões: em primeiro lugar, por englobar os domínios da saúde, atividade física, ambiente ocupacional e percepção da qualidade de vida, domínios esses utilizados na maioria dos questionários que visam avaliar a qualidade de vida; em segundo lugar, porque o QVS-80 contém 80 questões curtas e de fácil e rápida aplicação, comparativamente a outros instrumentos, como o questionário The World Health Organization instrument to evaluate quality of life (WHOQOL-100) (WORLD HEALTH ORGANIZATION, 1997), que, apesar de ser mais abrangente, é composto por 100 perguntas mais extensas e, portanto, possui tempo de aplicação mais longo, o que poderia prejudicar a adesão de respondentes voluntários.

O QVS-80 apresenta três questões abertas; 23 de múltipla escolha, com duas a quatro opções e 54 baseadas na Escala Likert. O questionário é dividido em quatro partes, chamadas "domínios". Os quatro domínios do questionário foram assim denominados:

- D1 - Domínio da Saúde

- D2 - Domínio da Atividade Física

- D3 - Domínio do Ambiente Ocupacional

- D4 - Domínio da Percepção da Qualidade de Vida

Com a soma das pontuações propostas pelos autores, faz-se a interpretação dos resultados e se classificam os índices obtidos no questionário. Para propiciar a apreciação, adotou-se como padrão uma escala centesimal, na avaliação final dos resultados dos domínios e da qualidade de vida geral obtida por este instrumento. A escala varia de 0 a 100 pontos, na qual o 0 corresponde à pior qualidade de vida, e o 100, à melhor qualidade de vida. Os resultados dos domínios e geral do QVS-80 foram padronizados em uma mesma escala (LEITE et al., 2012).

Para calcular o escore do QVS-80, sendo a pontuação mínima 54 e a máxima 270, a pontuação é convertida em percentual e foi ilustrada na Figura 1, abaixo.

Figura 1 - Pontos de corte da escala de resposta do QVS-80

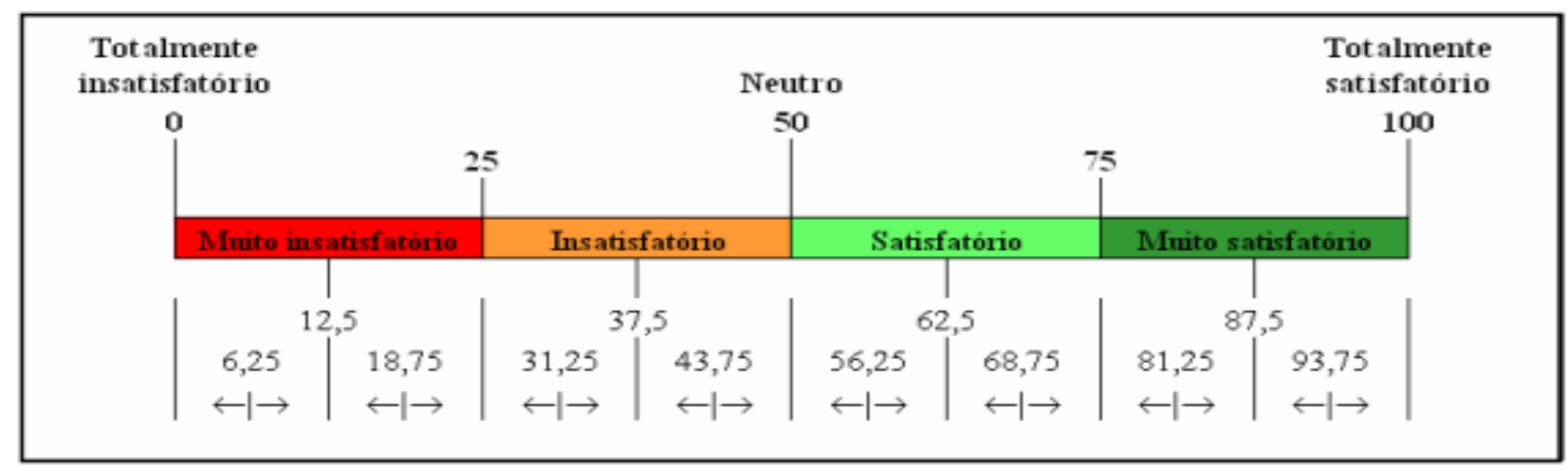

Fonte: Dados de pesquisa (questionário aplicado). 
O instrumento foi aplicado em meio digital, com o auxílio da ferramenta Formsus, um serviço de criação de formulários para viabilizar, de forma simples e ágil, o processo de coleta e disseminação de dados por meio da Internet.

A confecção da ferramenta de coleta de dados (desenvolvimento do formulário na ferramenta citada) ocorreu em julho de 2014, com teste piloto realizado com seis respondentes do Serviço de Qualidade de Vida e Reabilitação Funcional, tendo sido necessárias duas adaptações de texto, devido a dúvidas quanto ao enunciado da questão (questões 13 e 41), uma correção de erro de digitação e um ajuste quanto ao desenvolvimento do formulário na ferramenta. Na questão 13, foi considerado "desconforto" algum incômodo ou dor, e, na questão 41, considerou-se a realização de atividade física por indicação médica e também por outros profissionais de saúde.

A população da pesquisa foi composta por 3059 servidores efetivos do Senado Federal, número obtido no Portal Transparência e Controle Social da instituição em setembro de 2014. Como a pesquisa foi direcionada somente a servidores efetivos, antes do QVS-80, foi incluída uma questão que perguntava se o respondente se declarava servidor efetivo.

Optou-se pela amostragem por conveniência, em vez de probabilística, devido ao curto tempo disponível para aplicação e coleta de dados, análise dos resultados e conclusão do trabalho, após a disponibilização pelo Ministério da Saúde da ferramenta Formsus. Esse método apresenta limitações, porque os resultados e as conclusões se aplicam à amostra constituída (226 respondentes), não podendo ser generalizados com confiança para todo o universo de servidores efetivos (3059). Apesar dessas limitações, os resultados poderão ser utilizados como piloto para investigações posteriores, já que, até o momento, nenhum levantamento deste tipo havia sido realizado no âmbito do Senado Federal. Foi remetida à lista de e-mails dos servidores uma mensagem eletrônica, contendo as informações e o link da pesquisa.

As informações para o preenchimento do questionário constavam no link disponibilizado para seu preenchimento. O questionário ficou disponível de 18 de agosto a 17 de setembro de 2014, período em que houve adesão de 231 respondentes à pesquisa, dentre os quais 226 responderam serem servidores efetivos, e cinco (2\%) responderam ser comissionados.

Após o fechamento do período de disponibilidade da pesquisa, os 226 questionários dos servidores que se declararam efetivos foram tabulados e analisados.

\section{Análise dos resultados}

De acordo com a metodologia aplicada e a análise das respostas obtidas, apresentamse, a seguir, os resultados em relação aos quatro domínios descritos na seção referente à metodologia, ou seja, Domínio da Saúde (D1), Domínio da Atividade Física (D2), Domínio do Ambiente Ocupacional (D3) e Domínio da Percepção da Qualidade de Vida (D4). 
4.1. Domínio da Saúde (D1): resultado muito satisfatório com 80,5\%.

Esse domínio consta de 30 questões. As primeiras estão relacionadas à identificação do pesquisado: idade, peso, altura, renda familiar mensal, sexo, estado civil, grau de instrução, tempo de serviço no Senado Federal e função.

A segunda parte desse domínio engloba perguntas sobre doenças crônicas, qualidade do sono, atividades de lazer e hábitos relacionados ao uso de tabaco e bebida alcoólica. Os gráficos 1, 2, 3, 4, 5, 6, 7, 8, 9 e 10, analisados a seguir, mostram os resultados mais relevantes.

A pesquisa teve 226 questionários respondidos por servidores efetivos. Praticamente, metade por homens e metade por mulheres. A média de idade foi de 37 anos (37 anos para as mulheres e 38 anos para os homens) e a média de peso foi de $74 \mathrm{~kg}$ (64 kg para as mulheres e

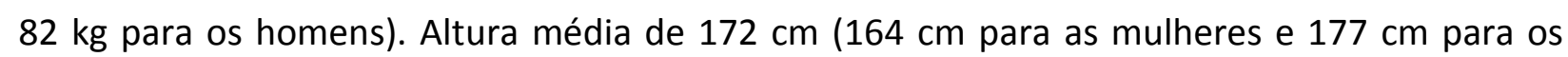
homens).

Com os valores obtidos de peso e altura, foi possível calcular o "Índice de Massa Corpórea" (IMC), ou BMI (Body Mass Index), em inglês. É uma medida simples do peso em relação à altura, utilizada para calcular o excesso de peso ou a obesidade dos adultos. A Organização Mundial de Saúde - OMS define o excesso de peso como sendo um IMC igual ou superior a 25, e a obesidade como sendo um IMC igual ou superior a 30.

O IMC médio dos servidores avaliados foi de 25 , sendo 23,5 para as mulheres e 26,0 para os homens. O IMC médio das mulheres foi classificado como peso normal (entre 18,5 a $24,9)$, com baixo risco de doenças relacionadas à obesidade, enquanto que o IMC médio dos homens foi classificado como excesso de peso (entre 25,0 e 29,9 ).

Tabela 1 - IMC dos participantes, por sexo

\begin{tabular}{cccc}
\hline \multicolumn{1}{c}{ IMC } & Homens & Mulheres & Total \\
\hline Excesso de peso & $27 \%$ & $10 \%$ & $37 \%$ \\
Obesidade & $6 \%$ & $3 \%$ & $9 \%$ \\
Soma & $33 \%$ & $13 \%$ & $46 \%$ \\
\hline
\end{tabular}

Fonte: Dados da pesquisa.

De todo o conjunto de pesquisados, somados homens e mulheres, quase metade apresentou excesso de peso ou obesidade. "A OMS descreve a obesidade como uma epidemia conectada a diversas doenças não transmissíveis, entre as quais, diabetes tipo 2, câncer e doenças cardíacas" (FOLHA DE SÃO PAULO, 2014). Relatório recente da consultoria McKinsey para o Reino Unido, também publicado na Folha de São Paulo, estima o custo mundial da obesidade em US\$2,1 trilhões - ou quase 3\% de tudo que a economia global produz.

Dos pesquisados, 70\% trabalham no Senado há até 5 anos; $15 \%$ têm de 6 a 20 anos de Casa; e 15\% mais de 20 anos. Em comparação, o Senado apresenta 3059 servidores efetivos em seu quadro (valor obtido no Portal Transparência e Controle Social em setembro de 2014), dentre os quais 34\% têm tempo de serviço até 5 anos; $16 \%$ de 6 a 20 anos; e $50 \%$ mais de 20 
anos. Dos servidores com mais de 20 anos, há 444 (por volta de $25 \%$ desse grupo) que já teriam direito à aposentadoria integral. Percebe-se que houve uma participação maior na pesquisa de servidores novos, e uma participação menor do grupo com mais tempo de serviço. A grande maioria dos servidores trabalha de manhã e à tarde, com turno fixo. Um terço deles está em posição de chefia.

Com relação à identificação, temos $56 \%$ homens e $44 \%$ mulheres; $33 \%$ solteiros; $58 \%$ casados; $9 \%$ separados ou divorciados; menos de $1 \%$ com ensino médio; quase $25 \%$ com ensino superior; $60 \%$ com pós-graduação lato sensu (especialização); $15 \%$ com pós-graduação stricto sensu (mestrado ou doutorado). Esse quesito demonstra que o grupo avaliado de servidores efetivos do Senado é bastante qualificado, já que 75\% dos respondentes apresentam pelo menos especialização, e menos de $1 \%$, ensino médio - ou seja - mesmo para os cargos de técnico legislativo (que exige apenas ensino médio), a maioria absoluta da amostra pesquisada apresenta pelo menos curso superior (Gráfico 1).

\section{Gráfico 1 - Grau de instrução (Questão 3)}

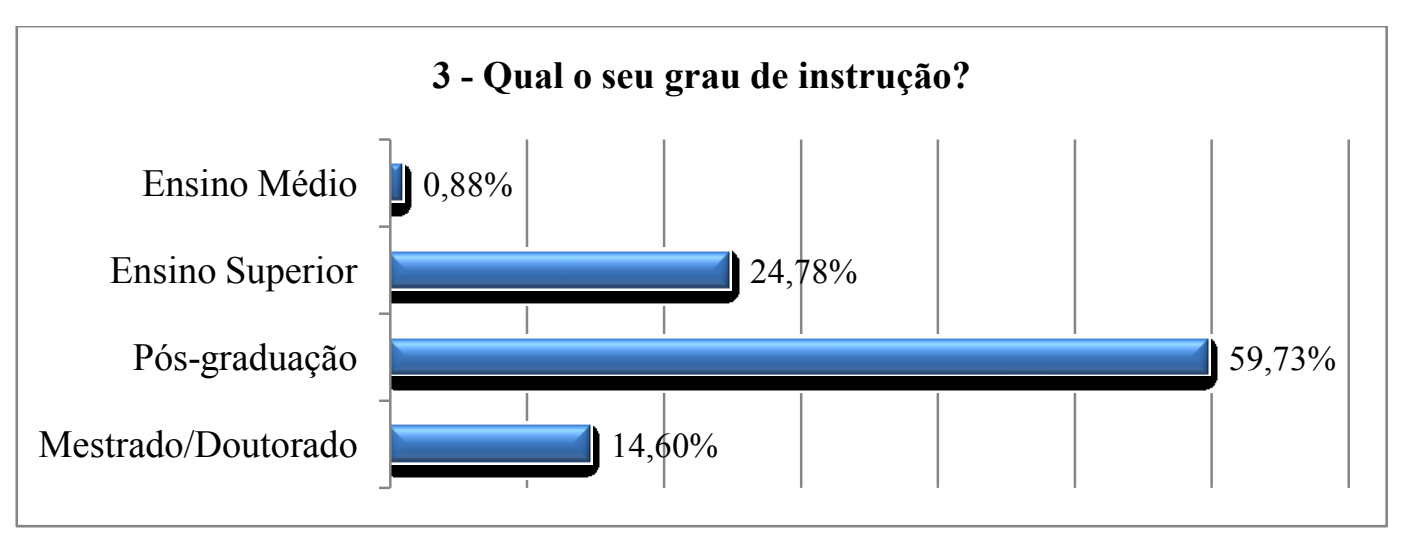

Fonte: Dados da pesquisa.

No Gráfico 3, sobre doenças apresentadas atualmente, $20 \%$ dos respondentes disseram apresentar asma/bronquite/rinite. Essas doenças podem ter uma prevalência aumentada, ou diminuída, dependendo da época do ano (períodos de maior ou menor umidade do ar). Já as outras alternativas dessa questão (diabetes, colesterol alto e pressão arterial alta) não mudam significativamente com as estações do ano. Segundo a Pesquisa Nacional de Saúde, 4,4\% de pessoas de 18 anos ou mais referiram diagnóstico médico de asma (ou bronquite asmática) no Brasil (IBGE, 2013). 


\section{Gráfico 2 - Principais doenças dos servidores (questão 9)}

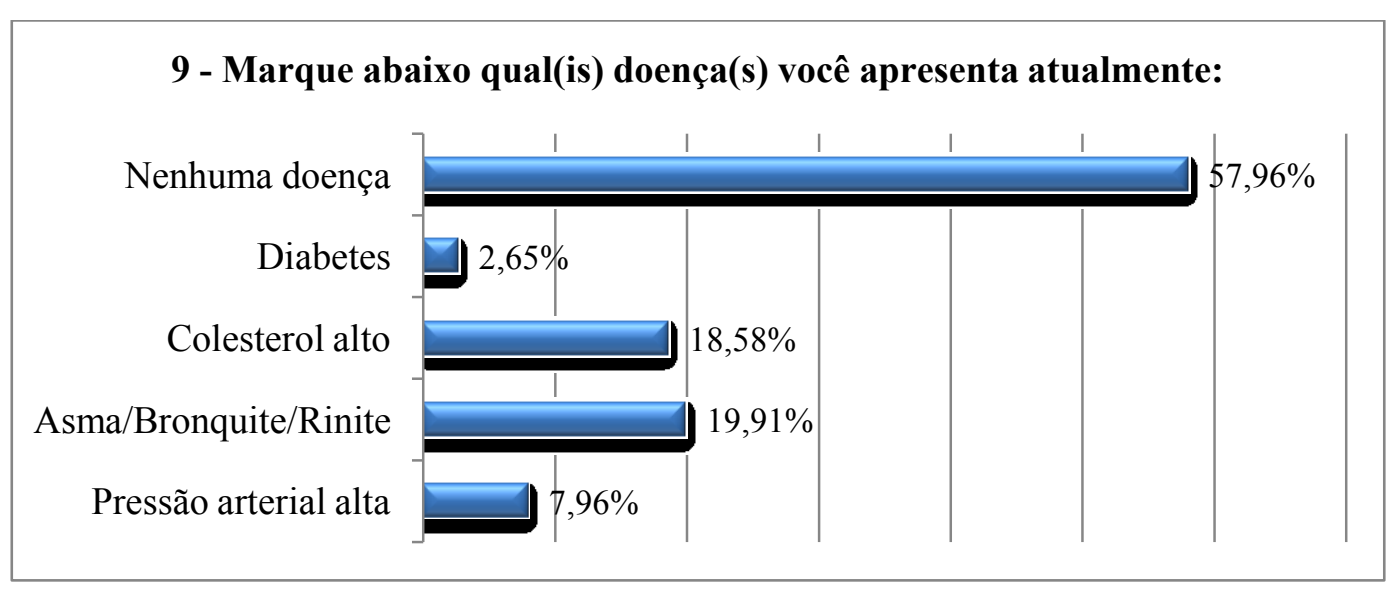

Fonte: Dados da pesquisa.

Mais da metade dos pesquisados respondeu não apresentar nenhuma das seguintes doenças crônicas: diabetes, colesterol alto, asma/bronquite/rinite ou pressão arterial alta. Por outro lado, 2,6\% referem ter diabetes, e 8\%, pressão arterial alta. A Pesquisa Nacional de Saúde (PNS), realizada em 2013, estimou que, no Brasil, 6,2\% da população de 18 anos ou mais referiram diagnóstico médico de diabetes, valor maior que o encontrado no grupo estudado. Ainda segundo a PNS, com relação à hipertensão arterial sistêmica, no Brasil, a prevalência é de $21,4 \%-2,5$ vezes mais que o encontrado neste trabalho.

\section{Gráfico 3 - Outras doenças (questão 10)}

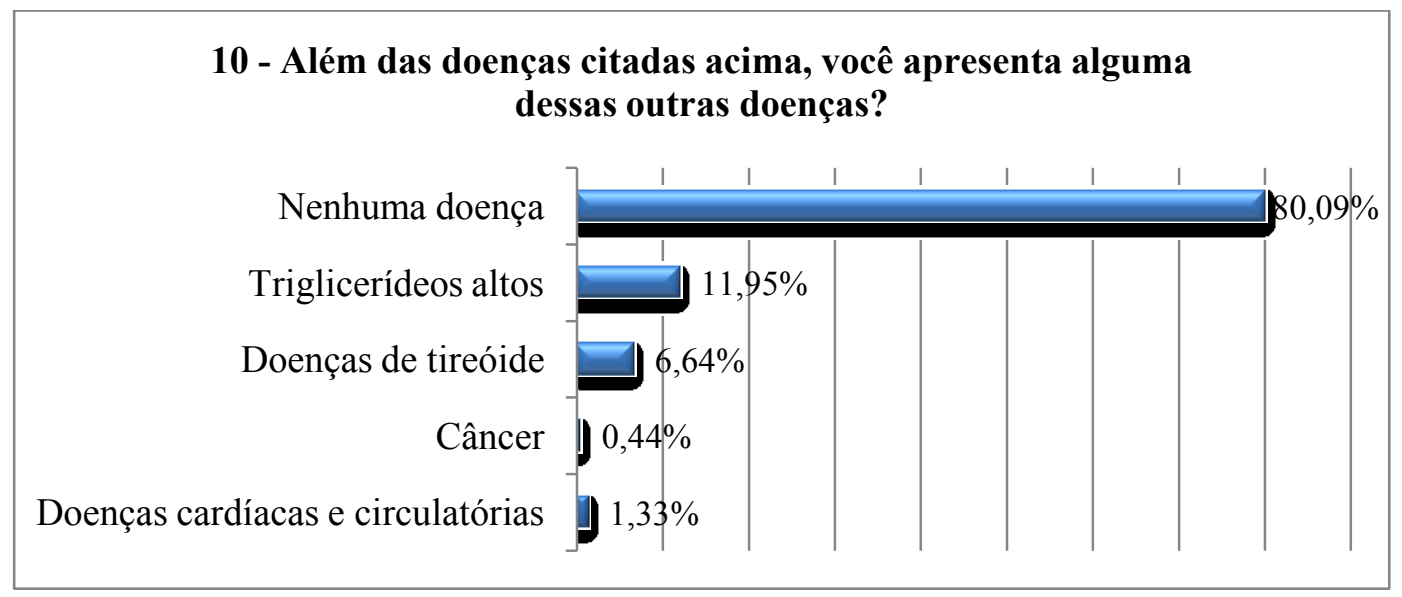

Fonte: Dados da pesquisa.

Apesar de a maioria dos avaliados afirmar não apresentar doenças crônicas, por volta de $75 \%$ relatam que familiares (pai, mãe, irmãos ou avós) apresentam ou faleceram por problemas relacionados a diabetes, colesterol alto, asma/bronquite/rinite, hipertensão arterial, triglicérides altas, tireoideopatias, câncer ou doenças cardíacas e circulatórias. Medidas preventivas como dieta saudável, controle do peso corporal, atividade física e exames 
preventivos de rotina podem evitar ou retardar seu aparecimento, impedindo que essas pessoas tenham os mesmos problemas que seus familiares tiveram, quando atingirem uma idade mais avançada.

"O estudo de fatores de risco, isolados ou combinados, tem permitido estabelecer relações de causa/efeito entre eles e determinadas doenças". Acrescenta-se que "[...] os fatores de risco podem ser encontrados no ambiente físico, serem herdados, ou representarem hábitos ou costumes próprios de um determinado ambiente social e cultural" (INSTITUTO NACIONAL DO CÂNCER). Fatores de risco comuns e modificáveis, como "obesidade, sedentarismo, tabagismo e alcoolismo" (ORGANIZAÇÃO PAN-AMERICANA DA SAÚDE, 2005), estão na base das principais doenças crônicas. Esses fatores "[...] explicam a grande maioria das mortes causadas por doenças crônicas em todas as idades, em ambos os gêneros e em qualquer parte do mundo". O mesmo fator pode ser de risco para várias doenças, por exemplo, o tabagismo é fator de risco de diversos cânceres e de doenças cardiovasculares e respiratórias (ANS, 2011, p. 13).

\section{Gráfico 4 - Doenças de familiares (questão 11)}

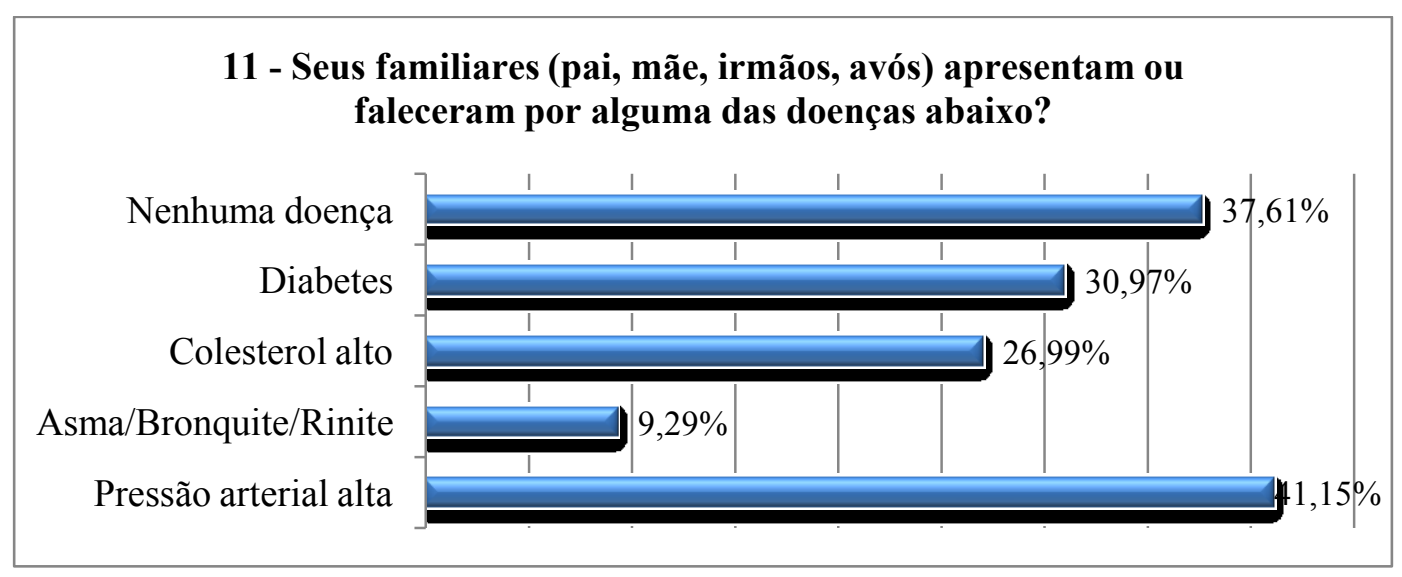

Fonte: Dados da pesquisa.

Número considerável de pesquisados (70\%) respondeu que sente desconforto corporal, sendo que desses, mais de $40 \%$ sentem desconforto na coluna (Gráfico 5). Também foram comuns queixas de dores na cabeça, olhos e membros superiores e inferiores. Essa quantidade é elevada e deve ser motivo de atenção, já que essas dores podem ser causadas por um problema de ergonomia, má postura, movimentos repetitivos ou sintomas de outras doenças, por exemplo. Dores no corpo são motivos frequentes de licenças médicas, afastamentos do trabalho e até aposentadoria precoce por motivo de saúde. No Senado Federal, por exemplo, recente pesquisa realizada com uma amostra aleatória representativa dos servidores da Casa, mostrou que $73 \%$ dos homens e $63,2 \%$ das mulheres referem sentir algum tipo de dor (SENADO FEDERAL, 2013c).

Melecchi (2014) refere que, de acordo com dados do INSS, “[...] as lesões por esforços repetitivos" - que geralmente resultam em dor - "[...] são a segunda causa de afastamentos do 
trabalho no Brasil". De acordo com a Organização Mundial de Saúde, 1\% dos trabalhadores é portador da síndrome. Ainda segundo a autora, "[...]entre os profissionais mais suscetíveis a desenvolver distúrbios osteomusculares relacionados ao trabalho (DORT) estão os digitadores, jornalistas e secretárias" (para nossa realidade, podemos incluir nesta lista os taquígrafos). Como o Senado possui muitos servidores nessas áreas, e como tanto a pesquisa de dor mencionada acima (SENADO FEDERAL, 2013c) como nossos resultados apontaram grande número de servidores com dores osteomusculares, a Organização deve estar atenta a esse problema, a fim de tomar medidas que busquem diagnosticar, prevenir e diminuir a prevalência de DORT no nosso meio. Se for detectado logo, cerca de $90 \%$ dos casos melhoram em poucos meses de tratamento.

\section{Gráfico 5 - Locais do corpo que apresenta desconforto (questão 13)}

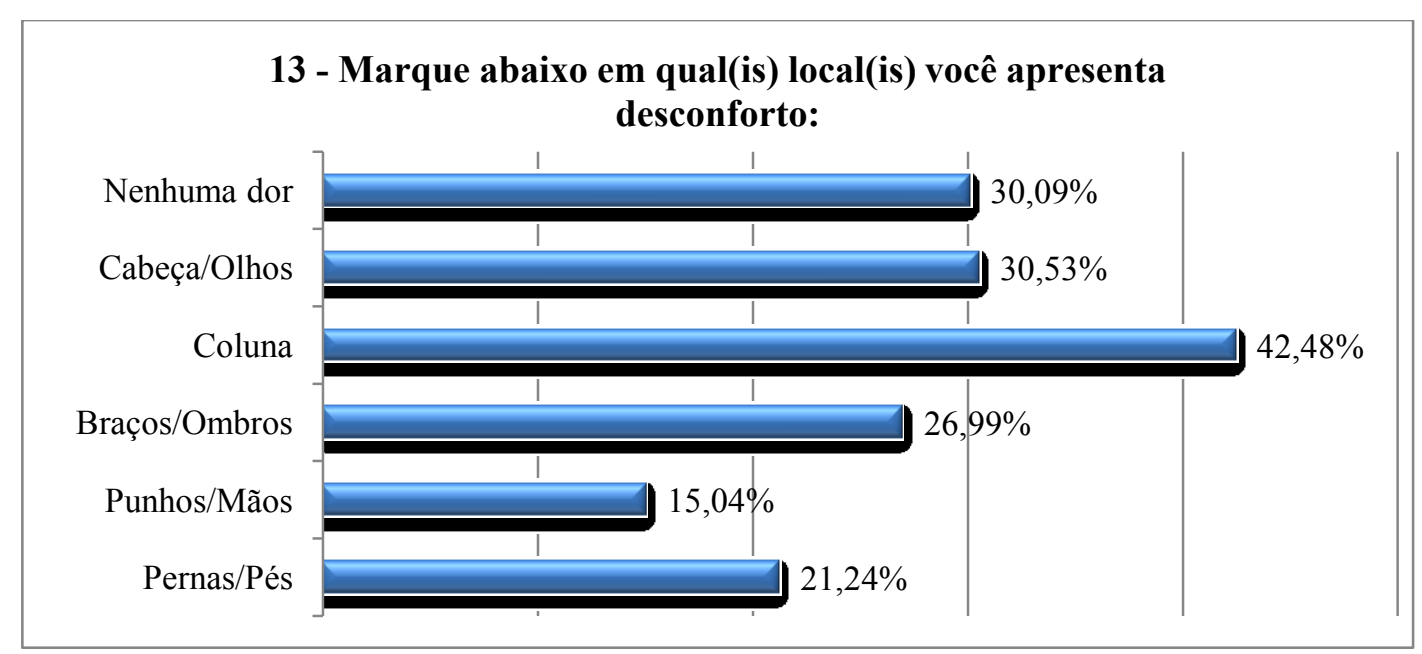

Fonte: Dados da pesquisa.

Com relação à análise subjetiva da própria saúde, quase $80 \%$ dos avaliados consideram sua saúde boa ou excelente (Gráfico 6). Essa questão é relevante para a análise da qualidade de vida (fatores subjetivos que a compõem), já que representa a impressão que o pesquisado tem da sua vida e do seu bem-estar. No que cerne às relações familiares, $83 \%$ consideram excelente ou boa sua vida em família, o que é um valor elevado e positivo, já que, do ponto de vista médico, ter continência familiar é um fator protetor da saúde, principalmente no tocante à saúde mental (ALMEIDA-PRADO; FÉRES-CARNEIRO, 2010). 
Gráfico 6 - Grau atual de saúde (questão 14)

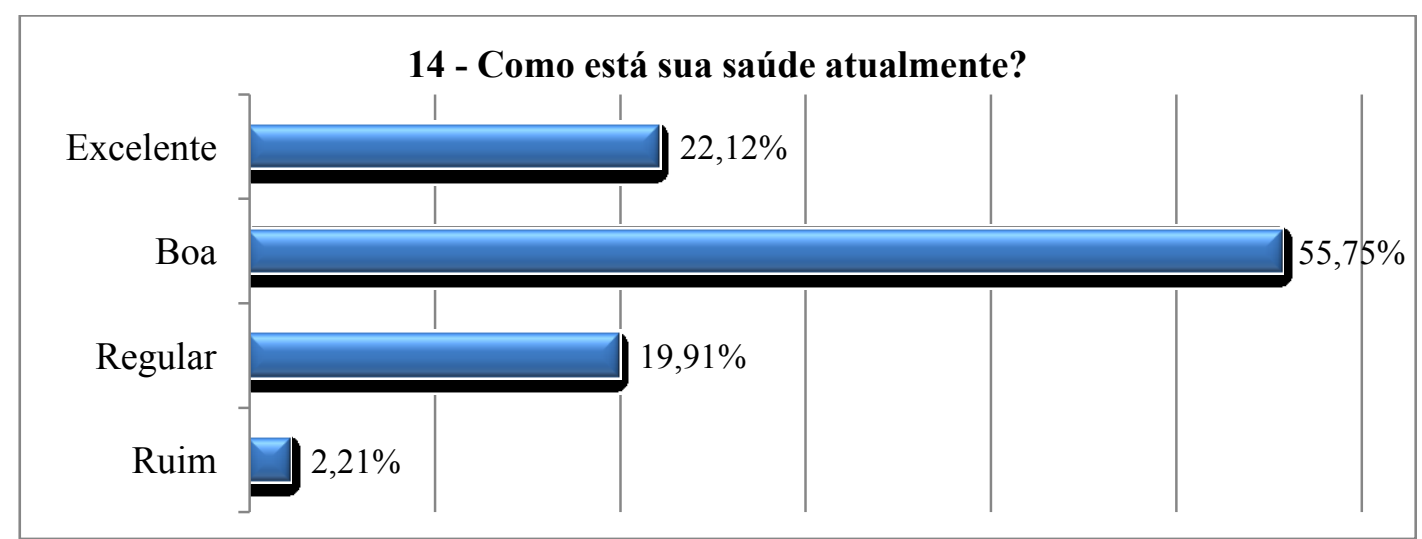

Fonte: Dados da pesquisa

Já no que se refere ao sono, um pouco mais de $40 \%$ o consideram regular, ruim ou muito ruim. Por volta de $20 \%$ dormem menos de 6 horas por dia. No questionário, há muitas perguntas relacionadas ao sono, porque insuficiente quantidade de horas dormidas e, principalmente, prejuízo na qualidade do sono produzem muitas alterações no indivíduo, como dificuldade de atenção e concentração, diminuição da energia, alteração do humor, diminuição da libido, entre outras alterações. Isso, evidentemente, acarreta queda na qualidade de vida do indivíduo.

Em relação ao cigarro, a grande maioria, quase $80 \%$, nunca fumou, e quase $10 \%$ pararam de fumar há pelo menos um ano, resultando em mais de $90 \%$ de não fumantes no universo pesquisado. No Brasil, a prevalência de usuários de produtos derivados de tabaco é de 15\% (IBGE, 2013). De acordo com o Instituto Nacional do Câncer, 200 mil pessoas morrem, por ano, em decorrência da exposição aos produtos do tabaco (INSTITUTO NACIONAL DO CÂNCER, 2014). Além disso, de acordo com a FIOCRUZ (2010), o tabagismo é “[...] a principal causa de morte evitável e fator de risco para seis das oito doenças que mais matam, dentre elas infarto do miocárdio, acidente vascular cerebral, doença pulmonar obstrutiva crônica e tuberculose".

Em 2014, o Ministério da Saúde regulamentou, por meio do Decreto Presidencial $8262 / 2014$, nova lei antifumo, estabelecendo que, em todo o país, ambientes fechados de uso coletivo devem estar $100 \%$ livres de tabaco. Por meio dessa lei, estão extintos os fumódromos. Em locais públicos fechados ou parcialmente fechados por um toldo, por exemplo, fica proibido o consumo específico de cigarros, cigarrilhas, charutos, cachimbos, narguilés e outros produtos derivados do tabaco. Para se adequar ao referido decreto, o Senado publicou em seu Boletim Administrativo o Ato do $1^{\circ}$ Secretário $12 / 2014^{5}$, tratando do assunto, além de lançar campanha, coordenada pelo Programa de Atenção ao Álcool e Drogas (Progad), para orientar e conscientizar seus servidores sobre o tema (Gráfico 10).

\footnotetext{
${ }^{5}$ Em 21 de agosto de 2014.
}

COLÓQUIO - Revista do Desenvolvimento Regional - Faccat - Taquara/RS - v. 14, n. 2, jul./dez. 2017 
A pesquisa também mostrou que quase $70 \%$ dos avaliados fazem uso de bebida alcoólica (Gráfico 7). De acordo com o IBGE (2013), o percentual da população com 18 anos ou de mais idade que costumava consumir bebida alcoólica uma vez ou mais por semana foi de $24,0 \%$. Considerando o uso de mais de 10 doses/semana como abusivo, no Senado, entre os servidores efetivos avaliados, esse valor foi de 7,5\%. Esses dados são preocupantes, porque o comportamento de uso abusivo pode progredir para a Síndrome de Dependência do Álcool. De acordo com o Código Internacional de Doenças - CID 10 (OMS, 1997), tal síndrome se caracteriza por um desejo intenso de beber e necessidade de ingerir doses cada vez maiores para se obter o mesmo efeito. As atividades da pessoa passam a girar em torno da obtenção de bebida, e ocorrem prejuízos nas demais atividades, como queda do rendimento no trabalho e faltas frequentes.

\section{Gráfico 7 - Consumo semanal de bebidas alcóolicas (questão 30)}

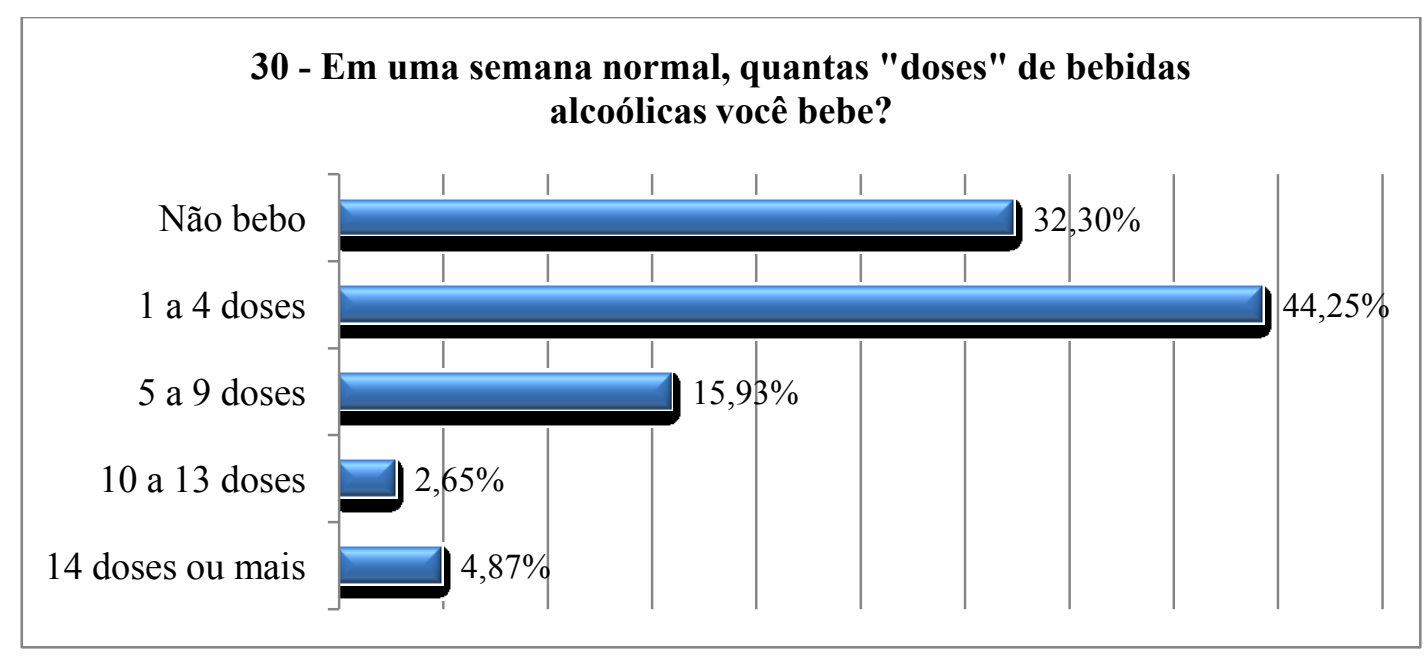

Fonte: Dados da pesquisa.

Dados do Instituto Nacional do Seguro Social (INSS) mostram "[...]o aumento de concessões de auxílios-doença relacionados ao uso de álcool e drogas no Brasil". De acordo com o órgão, em 2013, por volta de 135 mil benefícios foram concedidos, ante 126,5 mil em 2012, sendo que "[...] o alcoolismo foi o problema que mais provocou afastamento de trabalhadores" (PRATES; DANA, 2014). Entre 2009 e 2013, o número aumentou cerca de 19\%. O alcoolismo provoca diminuição acentuada da qualidade de vida do indivíduo e também afeta familiares e outras pessoas que fazem parte do seu convívio. As campanhas preventivas são muito importantes para alertar os servidores sobre os prejuízos do uso de álcool e para buscar a diminuição da quantidade de faltas e licenças no Senado Federal.

4.2 Domínio da Atividade Física (D2): resultado satisfatório, mas muito próximo do minimamente satisfatório, com $51,8 \%$.

Esse domínio consta de 15 perguntas. Questiona-se sobre a prática regular de exercícios, quantidade de horas na semana destinadas à musculação, corrida, caminhada, 
atividades aquáticas, atividades esportivas, dança ou ginástica (Gráfico 8). Há perguntas sobre os motivos que incentivam a realização de exercícios físicos (por indicação médica, por prazer, por motivos estéticos, para melhorar a condição física ou pelas relações sociais). As duas últimas perguntas são sobre o tempo que o servidor fica sentado durante o expediente e com que frequência se desloca (caminha, sobe escadas) durante a jornada de trabalho.

\section{Gráfico 8 - Prática de exercícios físicos regularmente (questão 31)}

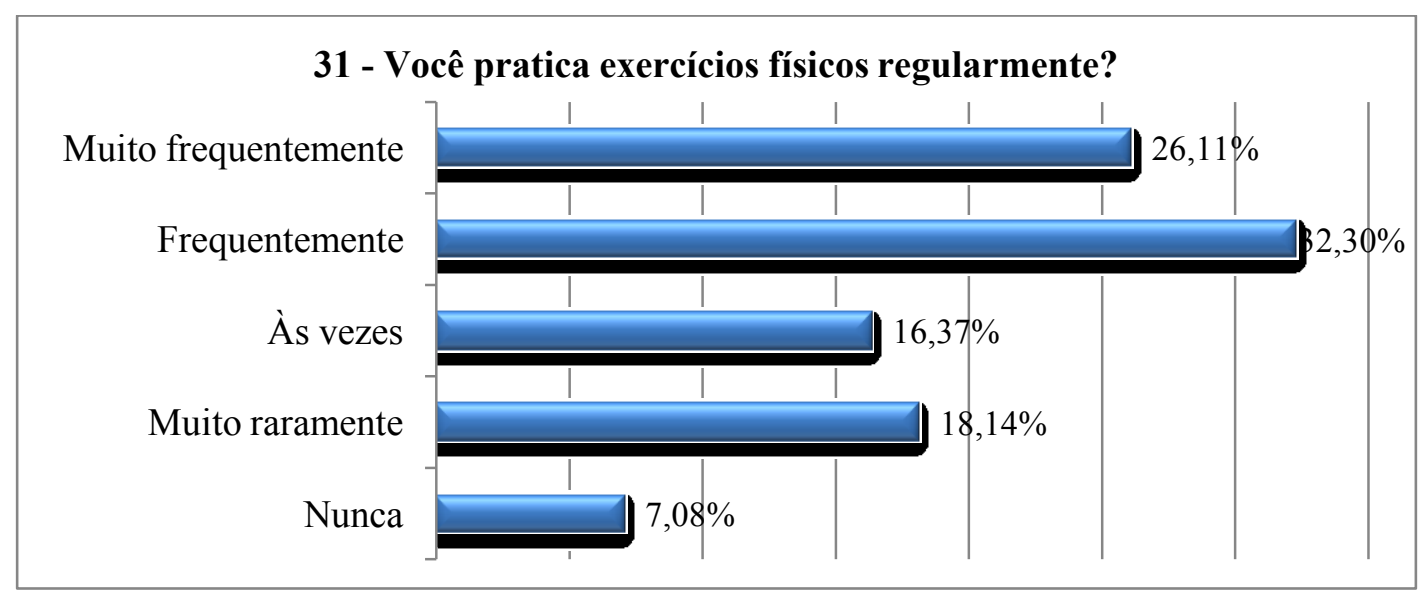

Fonte: Dados da pesquisa.

Pouco mais da metade dos servidores avaliados pratica atividade física regularmente, e $25 \%$, muito raramente ou nunca. A quantidade de adultos que praticavam o nível recomendado de atividade física diminuiu com o aumento da idade. Na faixa etária de 18 a 24 anos, 35,3\% praticavam o nível recomendado de atividade física. Entre os adultos de 25 a 39 anos de idade, a proporção foi de $25,5 \%$, e de $18,3 \%$ na faixa dos 40 a 59 anos, de acordo com o IBGE (2013). No trabalho, a maioria dos pesquisados passa muito tempo sentado e quase não se movimenta durante o expediente (Gráfico 9).

\section{Gráfico 9: Tempo sentado no trabalho (questão 44)}

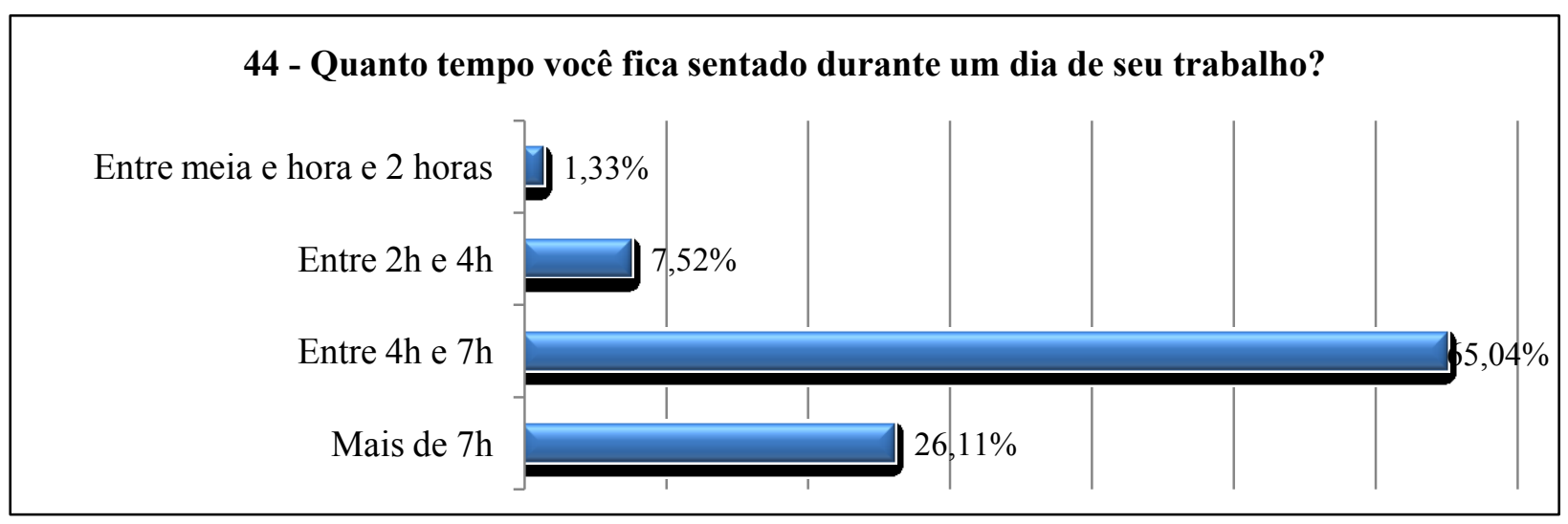

Fonte: Dados da pesquisa 
Esses resultados devem ser levados em consideração porque é notória a relação entre sedentarismo e aumento das taxas de obesidade e de doenças crônicas, ocorrendo o inverso com a prática regular de atividade física. Do ponto de vista físico, algumas das principais mudanças no organismo proporcionadas pela prática de exercícios são diminuição da pressão arterial, diminuição da resistência à insulina, redução da gordura corporal, aumento da massa e da força muscular. Do ponto de vista psíquico, melhora da autoestima, do humor e das funções cognitivas, gerando a diminuição do estresse e da ansiedade. A prática de exercícios físicos, além de promover a saúde, contribui na reabilitação de determinadas patologias que estão associadas ao aumento dos índices de morbidade (doença) e de mortalidade. Pesquisas mostram a associação entre pouca atividade física e o desenvolvimento de doenças cardiovasculares, câncer, diabetes e agravos à saúde mental, fatores que afetam também os trabalhadores (PITANGA; LESSA, 2005). Estimular a prática de exercícios físicos é, em última análise, objetivar a melhoria da qualidade de vida do servidor.

4.3 Domínio da Atividade Ocupacional (D3): resultado satisfatório, mas também bem próximo do minimamente satisfatório, com $51,8 \%$

Esse domínio consta de onze perguntas. As primeiras são sobre ginástica laboral. Entre os questionamentos, pergunta-se sobre a satisfação de realizar as atividades laborais, o volume de serviço, o clima na instituição e as condições do posto de trabalho. A maioria dos servidores (75\%) que participaram da pesquisa respondeu que, na seção em que trabalham, não é oferecida ginástica laboral e que nunca participaram dessa atividade, e $25 \%$ responderam que essa atividade lhes é oferecida - 16\% com instrutores próprios e $8 \%$ com instrutores de outra empresa ${ }^{6}$.

Com relação à satisfação de realizar seu trabalho no Senado Federal, metade da amostra assinalou estar satisfeita no ambiente de trabalho, e aproximadamente 15\% responderam negativamente, ou seja, disseram estar insatisfeitos na realização das suas atividades na instituição. De acordo com Marson et al. (2011, p. 3), “O comportamento do trabalhador é influenciado pelo seu ambiente organizacional, e (...) a motivação no desenvolvimento de suas atividades diárias pode facilitar ou dificultar o alcance dos objetivos". Além disso, segundo os autores, a frustração com o trabalho é fator contributivo para o estresse e, consequentemente, para o prejuízo da sua qualidade de vida no trabalho.

Para quase $60 \%$ dos avaliados, o volume de trabalho é adequado, contudo o posto de trabalho foi considerado regular, ruim ou muito ruim por mais de $40 \%$ deles. 0 impacto de um posto de trabalho sentido como ruim pelo servidor pode ser o aumento do absenteísmo,

\footnotetext{
${ }^{6}$ O serviço de ginástica laboral oferecido no Senado Federal é composto por analista legislativo fisioterapeuta e também por estagiários, e, por isso, a obtenção das respostas com instrutores próprios e instrutores de outra empresa.
} 
superando taxas administráveis e agravando as condições daqueles servidores que permanecem trabalhando e que passam a ter aumento da carga de trabalho.

Segundo Ferreira (2008), "[...] ausentar-se sistematicamente do trabalho termina funcionando para alguns trabalhadores como estratégia de preservar a própria saúde mental e física". Além disso, o autor ressalta que o custo estatal gerado por "[...] incapacidades temporárias e permanentes, afastamentos das atividades laborais, aposentadorias precoces" (FERREIRA, 2008) é muito alto, e medidas que possam reduzir esses problemas devem ser estimuladas em todos os órgãos governamentais. Por isso, oferecer ambientes e postos de trabalho seguros, salubres e agradáveis deve ser visto como ações que protegem a saúde do servidor, aumentam sua motivação e qualidade de vida, diminuem o absenteísmo e geram economia para o Senado e para o Estado Brasileiro, uma vez que aumenta a produtividade e diminui custos com pessoal.

4.4 Domínio da Percepção da Qualidade de Vida (D4): resultado satisfatório, muito próximo do muito satisfatório com $74,9 \%$.

Esse domínio consta de 24 perguntas. São perguntas mais subjetivas, que procuram avaliar como o pesquisado se sente em relação a vários aspectos de sua vida, como, por exemplo, percepção de sentido da vida e de quanto ela é aproveitada; aceitação da aparência física; disposição na realização das atividades diárias; condição financeira e presença ou ausência de sentimentos negativos relacionados ao humor.

Com relação à percepção sobre a própria qualidade de vida, mais de $70 \%$ consideraram muito boa ou boa, e apenas 3\% fizeram uma avaliação negativa, ruim ou muito ruim (Gráfico 10). Mais da metade dos servidores avaliados disseram aproveitar extremamente ou bastante a vida, e menos de $5 \%$ se sentem pouco seguros ou inseguros com relação à vida diária. Por volta de $25 \%$ dos respondentes referiram precisar pelo menos um pouco de tratamento médico no dia a dia. Metade da amostra respondeu positivamente à questão referente à oportunidade de atividades de lazer, e também metade está satisfeita com relação à vida sexual. Por volta de $10 \%$ disseram-se insatisfeitos ou muito insatisfeitos consigo mesmos.

A quase totalidade dos pesquisados responderam pelo menos "médio" à pergunta sobre ter dinheiro suficiente para satisfazer suas necessidades, e menos de $2 \%$ responderam "muito pouco", ou seja, pequena parcela dos avaliados poderia apresentar uma pior qualidade de vida por questões financeiras. 


\section{Gráfico 10 - Qualidade de vida (questão 57)}

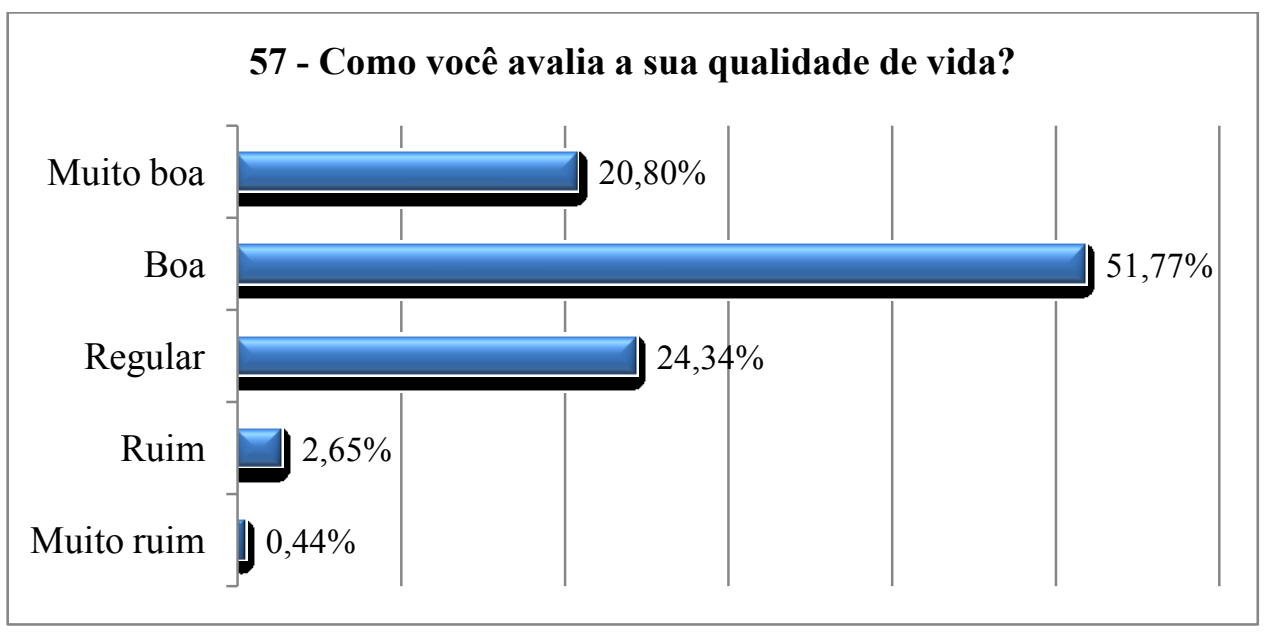

Fonte: Dados da pesquisa.

Mais da metade dos servidores avaliados responderam apresentar sentimentos negativos, tais como mau humor, desespero, ansiedade e depressão nas duas últimas semanas (33\% às vezes; por volta de $16 \%$, frequentemente; $4,5 \%$, muito frequentemente). Essa última questão do domínio 4 tem grande valor na medida em que avalia sintomas que podem fazer parte de patologias psiquiátricas, como depressão ou ansiedade, por exemplo. Podem não caracterizar doenças ainda, mas podem já ser os sintomas iniciais delas.

Vale lembrar que a média dos servidores pesquisados é de 37 anos, ou seja, são adultos de uma faixa etária jovem e que, na grande maioria, ainda têm pouco tempo de serviço no Senado (menos de 5 anos), mas já apresentam sintomas relacionados à depressão (70\% dos respondentes da pesquisa são novos servidores). Medidas preventivas bem aplicadas podem evitar que muitos servidores venham a adoecer no futuro, já que, com mais tempo de serviço pela frente, maiores as chances de ocorrerem episódios depressivos nesse intervalo de tempo.

$\mathrm{Na}$ avaliação global, ou seja, na totalidade do questionário em seus quatro domínios Saúde, Atividade Física, Ambiente Ocupacional e Percepção da Qualidade de Vida - o resultado encontrado foi de $64,7 \%$, indicando que, no geral, com a ferramenta utilizada para avaliação, a qualidade de vida do grupo de servidores efetivos do Senado Federal avaliado é considerada satisfatória.

\section{Considerações finais}

O objetivo geral foi avaliar de forma mais detalhada a qualidade de vida de um grupo de servidores que compõe o quadro de servidores efetivos do Senado Federal. A análise dos resultados da pesquisa, de acordo com a ferramenta utilizada - QVS-80, apontou uma amostra de servidores que apresenta uma satisfatória qualidade de vida, numa escala que vai de muito insatisfatória a muito satisfatória. 
Com relação aos objetivos específicos, o trabalho identificou, entre os principais problemas que afetam a qualidade de vida dos servidores pesquisados, o sobrepeso: quase metade da amostra declarou apresentar excesso de peso ou obesidade. Apesar de a maioria dos avaliados ter respondido não apresentar doenças crônicas, por volta de $75 \%$ dos familiares (pai, mãe, irmãos ou avós) apresentam-nas, ou faleceram por problemas que lhes são relacionados, como, por exemplo, diabetes e hipertensão arterial sistêmica. Um número considerável de pesquisados (70\%) respondeu que sente desconforto corporal, e quase $25 \%$ deles dormem menos de 6 horas por dia.

Um pouco mais da metade dos servidores avaliados pratica atividade física, ou seja, a outra metade é sedentária. A média brasileira da população masculina com 18 anos ou mais, que pratica o nível recomendado de atividade física no lazer, é de $22,5 \%$. Para as mulheres, este percentual é de 18,4\% (IBGE, 2013).

O posto de trabalho foi considerado regular, ruim, ou muito ruim por mais de $40 \%$ das pessoas pesquisadas, e mais da metade dos servidores avaliados respondeu apresentar sentimentos negativos, tais como mau humor, desespero, ansiedade e depressão nas duas últimas semanas anteriores à realização da pesquisa.

Entre os resultados positivos, pode-se destacar que o quadro de servidores efetivos do Senado é bastante qualificado - 75\% da totalidade apresentam pelo menos pós-graduação, e menos de $1 \%$ tem apenas ensino médio (questão 3 do QVS-80), o que, indiretamente, poderia facilitar o acesso a diversas dimensões de qualidade de vida, como o lazer.

Questionados com relação ao estado atual de sua saúde, quase $80 \%$ dos avaliados consideram-na excelente ou boa (questão 14 do QVS-80). Além disso, de acordo com a questão 29 do questionário QVS-80, 93\% do universo pesquisado são não fumantes. Com relação à diabetes e à pressão arterial alta, as prevalências encontradas na pesquisa foram menores que as prevalências da população brasileira (IBGE, 2013).

Segundo a questão 67 do questionário QVS-80, mais de $98 \%$ dos pesquisados apontararam pelo menos a opção "médio" à pergunta sobre ter dinheiro suficiente para satisfazer às suas necessidades, ou seja, pequena parcela dos avaliados poderia apresentar uma qualidade de vida ruim por questões financeiras.

A contribuição deste trabalho foi a de mostrar o retrato da qualidade de vida de um grupo de servidores do quadro efetivo do Senado Federal, ao identificar os principais fatores positivos e negativos que influenciaram esse resultado, além de oferecer dados estatísticos como, por exemplo, a quantidade de fumantes, quantidade de obesos, prevalência de doenças crônicas, entre outros dados obtidos pelo questionário QVS-80. Esse questionário também se apresenta como uma ferramenta para medição periódica da qualidade de vida do quadro de pessoal, revelando os problemas encontrados e sugerindo soluções.

No tocante às limitações do trabalho, com relação ao processo de amostragem, não se tratou de amostragem probabilística aleatória, de modo que os resultados são válidos para a amostra de servidores avaliados, mas não necessariamente para toda a população do Senado Federal. Isso ocorreu pela demora na confecção da ferramenta utilizada (Formsus), reduzindo 
muito o prazo de coleta dos resultados, avaliação e conclusão do trabalho. Sendo assim, o questionário foi disponibilizado inicialmente, por e-mail, para um grupo de novos servidores, e, num segundo momento, disponibilizado na intranet do Senado Federal, viabilizando o acesso a todos os servidores.

Conforme mostrado na análise, cerca de $70 \%$ das pessoas que responderam ao questionário estão no Senado há menos de 5 anos. São novos servidores, os quais representam $34 \%$ do quadro total de efetivos. Com mais de 20 anos na Casa, temos $50 \%$ do total, embora pouco mais de $15 \%$ das respostas tenham correspondido a esse grupo. Já a parcela de servidores que tem de 6 a 20 anos de tempo de serviço - 16\% do total do quadro efetivo - teve participação de $15 \%$ da pesquisa.

O resultado satisfatório obtido na pesquisa ilustra o panorama da situação atual do Senado, e muitas outras variáveis obtidas nesta pesquisa podem, de acordo com os interesses de outras pesquisas, ser comparadas com dados já conhecidos do Instituto Brasileiro de Geografia e Estatística (IBGE), do Ministério da Saúde ou da Organização Mundial de Saúde.

A aplicação do questionário QVS-80 de forma regular, por exemplo, de dois em dois anos, pode auxiliar na avaliação das ações e programas preventivos desenvolvidos pelo Senado e seu real impacto, comparando a qualidade de vida dos servidores da Casa em momentos diferentes. Questões podem ser levantadas, tais como Estão efetivamente tendo impacto as ações de promoção de saúde? Houve diminuição da quantidade de pessoas com excesso de peso e obesidade? Uma quantidade maior de servidores tem feito atividade física com regularidade? Aumentou o número de servidores satisfeitos com seu ambiente de trabalho?

A atenção com a saúde e a qualidade de vida deve ser uma preocupação de todos - dos senadores, diretores, coordenadores, chefes e todo o quadro de servidores. Há evidências demonstrando que investir na prevenção e na promoção da saúde, englobando a saúde mental, resulta em economia para os cofres públicos por ocasionar diminuição do absenteísmo, das licenças médicas e das aposentadorias por doença (ANS, 2011). Portanto, uma boa administração precisa investir não só na aquisição e manutenção de bens materiais, mas precisa cuidar bem dos seus servidores. O resultado final disso é a melhoria na prestação dos serviços para a sociedade brasileira, com um quadro de trabalhadores mais motivado, mais saudável e mais realizado profissionalmente.

O Senado tem praticado ações no sentido de melhorar a qualidade de vida dos seus servidores. Uma dessas ações foi regulamentada pelos Atos do Primeiro Secretário 10/2014 e da Diretoria Geral 8/2014, publicados no Boletim Administrativo do Senado Federal (BASF) ${ }^{7}$, que visam estimular o uso de bicicletas como meio de transporte pelos servidores da Casa. Foram autorizadas a criação de espaços especializados e a instalação de paraciclos em pontos estratégicos. Essa medida favorece a prática de atividade física, fortalece a saúde física e psíquica do servidor, contribui com a diminuição de veículos automotores nos arredores e, consequentemente, diminui a eliminação de gás carbônico, além de ser econômica. Esse é

\footnotetext{
${ }^{7}$ Publicados no BASF em 12 de junho e 13 de julho de 2014, respectivamente.
} 
apenas um exemplo de como a instituição pode modificar de forma significativa a vida de seus servidores, com um custo baixo e com muitos benefícios.

Os serviços de qualidade de vida das instituições visam oferecer suporte ao quadro de servidores e procuram elevar a qualidade de vida do quadro de pessoal. O Serviço de Qualidade de Vida e Reabilitação Funcional (SEQVR) do Senado, no intuito de atingir esses objetivos, atualmente oferece os seguintes programas: Alimento e Saúde, Caminhos para a Aposentadoria, Programa de Acompanhamento Funcional, Orientação Financeira, Pesquisa de Clima Organizacional, Desenvolvimento de Equipes de Trabalho, Programa de Atenção ao Uso de Álcool e Drogas (Progad), Pró-Saúde Ocupacional e Dignidade e Respeito no Trabalho.

Juntamente com a Medicina do Trabalho, Medicina Preventiva e a Diretoria de Gestão de Pessoas, esses serviços de qualidade de vida podem promover ações importantes com o objetivo de manter e melhorar a saúde dos indivíduos. A formação de grupos de trabalho multidisciplinar pode contribuir com o estudo de pontos mais sensíveis e que necessitam de intervenções específicas. Essas ações podem ser de vários tipos - artigos sobre saúde e prevenção na intranet, palestras de temas relacionados a esses assuntos, cursos de capacitação de gestores, aplicação de exames médicos periódicos, avaliação da viabilidade do trabalho por comutação para algumas áreas, flexibilização do horário de trabalho, entre outras.

Reaplicar o questionário QVS-80 no Senado Federal a todos os servidores, efetivos e comissionados, pode ser de grande valia, tendo em vista que o número de servidores comissionados é semelhante ao de efetivos, e conhecer essa população é muito importante para que a Secretaria de Gestão de Pessoas possa aprimorar as ações que visam melhorar a qualidade de vida de todos os trabalhadores.

Por fim, a aplicação de pesquisas com a medição do peso, da altura e a realização de alguns exames laboratoriais como glicemia, colesterol total e frações, função tiroidiana, entre outros exames de laboratório, poderia gerar dados estatísticos relacionados à saúde do servidor mais confiáveis que os obtidos apenas por respostas a questionários.

\section{Referências}

ANS. AGÊNCIA NACIONAL DE SAÚDE SUPLEMENTAR (BRASIL). Manual técnico de promoção da saúde e prevenção de riscos e doenças na saúde suplementar - 4. ed. rev. e atual. Rio de Janeiro, 2011.

ALMEIDA-PRADO, M. C. C.; FÉRES-CARNEIRO, T. Violência familiar: obesidade mórbida e função ômega. Revista Latino-americana de Psicopatologia Fundamental, São Paulo, v. 13, n. 2, p. 190-206, jun. 2010.

ASSOCIAÇÃO BRASILEIRA PARA O ESTUDO DA OBESIDADE E DA SÍNDROME METABÓLICA (ABESO). Diretrizes brasileiras de obesidade 2009/2010. 3. ed. Itapevi: AC Farmacêutica, 2009.

BRASIL. Decreto n. 8262, de 31 de maio de 2014. Altera o Decreto no 2.018, de 1ㅇ de outubro de 1996, que regulamenta a Lei no 9.294, de 15 de julho de 1996. Brasília, 2014. 
BUSS, P. M. Promoção da Saúde e Saúde Pública. Rio de Janeiro: ENSP, 2000.

CAVAZZA, J. Avaliação da saúde global, fatores de risco para doenças crônicas não transmissíveis e qualidade de vida em trabalhadores. 2012. 103f. Dissertação (Mestrado em Educação Física - Setor de Ciências Biológicas) - Universidade Federal do Paraná, Curitiba, 2012.

CONFERÊNCIA DAS NAÇÕES UNIDAS SOBRE MEIO AMBIENTE E DESENVOLVIMENTO/CNUMAD. Agenda 21. Brasília: Senado Federal, 1996.

IBGE. INSTITUTO BRASILEIRO DE GEOGRAFIA E ESTATÍ́STICA. Pesquisa nacional de saúde 2013: percepção do estado de saúde, estilos de vida e doenças crônicas - Brasil, grandes regiões e unidades da federação. Rio de Janeiro, 2014.

FAPESP. Mapa global da depressão. Agência Fapesp de notícias, 26/07/2011. Disponível em: <http://agencia.fapesp.br/mapa_global_da_depressao/14229/>. Acesso em: 19 dez. 2014.

FERREIRA, M.C. A ergonomia da atividade se interessa pela qualidade de vida no trabalho?: Reflexões empíricas e teóricas. Cadernos de Psicologia Social do Trabalho. São Paulo, v. 11, n. 1, jun. 2008. Disponível em: <http://pepsic.bvsalud.org/scielo.php?script=sci_arttext \&pid=S1516-37172008000100007\&lng=pt\&nrm=iso>. Acesso em: $18 \mathrm{dez} .2014$.

FIOCRUZ. Artigo avalia importância das campanhas contra o fumo em maços de cigarros. Agência Fiocruz de notícias, 30/07/2010. Disponível em: <http://www.agencia.fiocruz.br/artigoavalia-import\%C3\%A2ncia-das-campanhas-contra-o-fumo-em-ma\%C3\%A7os-de-cigarros>. Acesso em: 19 dez. 2014.

FOLHA DE SÃO PAULO. Obesidade já custa US\$ 2 trilhões ao mundo, aponta consultoria. Caderno Mercado, 27/11/2014. Disponível em:

<http://www1.folha.uol.com.br/mercado/2014/11/1553927-obesidade-ja-custa-us-2-trilhoesao-mundo-aponta-consultoria.shtml>. Acesso em: $18 \mathrm{dez} .2014$.

INSTITUTO NACIONAL DO CÂNCER (INCA). Observatório da política nacional de controle do tabaco. Disponível em: <http://www2.inca.gov.br/wps/wcm/connect/observatorio_ controle_tabaco/site/home/dados_numeros/mortalidade>. Acesso em: 19 dez. 2014.

Prevenção e fatores de risco. Disponível em:

<http://www1.inca.gov.br/conteudo_view.asp?id=13>. Acesso em: 18 dez. 2014.

LACAZ, F. A. Qualidade de vida no trabalho e saúde/doença. Ciência \& Saúde Coletiva, Rio de Janeiro, v. 5, n. 1, 2000. Disponível em:

$<$ http://www.scielo.br/scielo.php?script=sci_arttext\&pid=S1413-

$81232000000100013 \&$ Ing=pt\&nrm=iso>. Acesso em: 30 out. 2014.

LEITE, N. et al. Questionário de avaliação da qualidade de vida e da saúde - QVS-80 In: MENDES, R.; LEITE, N. Ginástica Laboral: Princípios e Aplicações Práticas. Barueri: Manole, 2012.

LUCENA, R.; VERSOLATO, M. Depressão já é a doença mais incapacitante, afirma OMS. Jornal Folha de São de Paulo, Caderno Equilíbrio e Saúde. Acesso em: 17 dez. 2014. 
MARSON, L. S. C. et al. A relação entre motivação e Qualidade de vida no trabalho: um estudo com técnicos administrativos de uma universidade pública do estado do Rio de Janeiro.

VII Congresso Nacional de Excelência em Gestão, Rio de Janeiro, 2011.

MELECCHI, D. 28 de fevereiro - Dia Mundial de combate a LER/DORT. Disponível em: <http://www.fenafar.org.br/fenafar/crf/item/7522-28-de-fevereiro-\%E2\%80\%93-dia-mundialde-combate-a-ler-dort-por-debora-melecchi>. Acesso em: 18 dez. 2014.

MINAYO, M.C.; HARTZ, Z.M.; BUSS, P.M. Qualidade de vida e saúde: um debate necessário. Ciência \& Saúde Coletiva, Rio de Janeiro, v. 5, n. 1, 2000.

MINISTÉRIO DA SAÚDE. Promoção da Saúde: Cartas de Ottawa, Adelaide, Sundsvalle e Santa Fé de Bogotá. Brasília: MS/IEC, 1996.

MONACO, F.; GUIMARÃES, V. Gestão da qualidade total e qualidade de vida no trabalho: o caso da Gerência de Administração dos Correios. Revista de Administração Contemporânea. Curitiba. v. 4, n. 3, Dec. 2000. Disponível em:

$<$ http://www.scielo.br/scielo.php?script=sci_arttext\&pid=S141565552000000300005\&lng=en\&nrm=iso>. Acesso em: 18 jan. 2014.

NASCIMENTO, R. H. Qualidade de Vida no trabalho. 2013. Disponível em: http://www.hospvirt.org.br/enfermagem/port/qvt.html. Acesso em: 20 dez. 2014.

ORGANIZAÇÃO MUNDIAL DA SAÚDE (OMS). CID-10 Classificação Estatística Internacional de Doenças e Problemas Relacionados à Saúde. 10. rev. São Paulo: EDUSP, 1997.

ORGANIZAÇÃO PAN-AMERICANA DA SAÚDE (OPAS). Prevenção de doenças crônicas: um investimento vital. Brasília: Organização Mundial da Saúde, 2005.

PITANGA, F. J.; LESSA, I. Prevalence and Variables Associated with Leisure-time Sedentary Lifestyle in Adults. Cadernos de Saúde Pública, v. 21, n. 3, p. 870-877, 2005.

PRATES, C.; DANA, D. Cresce o número de afastamentos no INSS por uso de álcool e drogas. Publicado em 05/03/2014. Disponível em:

http://www.previdenciatotal.com.br/integra.php?noticia=1721. Acesso em: 19 dez. 2014.

PROGRAMA DAS NAÇÕES UNIDAS PARA O DESENVOLVIMENTO (PNUD) - Material de Apoio: Perguntas Frequentes. Desenvolvimento Humano, IDH e IDHM. 2013. Disponível em: <http://www.pnud.org.br/arquivos/faq-atlas2013.pdf>. Acesso em: 6 jan. 2015.

ROBBINS, S. Comportamento organizacional. São Paulo: Pearson Higher Education, 2005.

SENADO FEDERAL. Serviço de Qualidade de Vida e Reabilitação Funcional - SEQVR. Relatório final das atividades desenvolvidas pelo SEQVR em 2013. Trabalho não publicado. Brasília, 2013a.

. Relatório preliminar do grupo de trabalho: Revisar as doenças que motivam os afastamentos dos servidores do Senado Federal e propor ações relativas à saúde ocupacional. Trabalho não publicado. Brasília, 2013b. 
. Serviço de Qualidade de Vida e Reabilitação Funcional - SEQVR. Relatório- Pesquisa de opinião: Prevalência de Sintomas Osteomusculares em Servidores do Senado Federal. Trabalho não publicado. Brasília, 2013c.

SEGRAF, 2014.

Cartilha do Serviço de Qualidade de Vida e Reabilitação Funcional - SEQVR. Brasília:

. Ato do $1^{\circ}$ Secretário n. 12, de 21 de agosto de 2014. Dispõe sobre as restrições ao uso de produtos fumígenos nos espaços do Senado Federal. Brasília, 2014.

. Ato do $1^{\circ}$ Secretário n. 10, de 12 de junho de 2014. Brasília, 2014.

. Ato da Diretoria Geral n. 8, de 3 de julho de 2014. Regulamenta o ato do Primeiro Secretário n. 10 de 2014. Brasília, 2014.

SOUZA, J. F. V.; CANDIOTO, R. A. Qualidade de vida e meio ambiente: um debate para mudanças socioeconômicas e políticas no Brasil. Cadernos de Direito. Piracicaba, v. 13, n. 24, p. 9-34, jan./jun. 2013.

WORLD HEALTH ORGANIZATION. WHOQOL: measuring quality of life. Genebra: WHO, 1997. 